\title{
APLIKASI SISTEM INFORMASI PEMESANAN PAKET PERNIKAHAN BERBASIS WEB \\ (Studi Kasus : SANGGAR LARAS WEDDING BOGOR)
}

\author{
Muhammad ${ }^{1}$, \\ ${ }^{1}$ Sistem Informasi, STMIK Nusa Mandiri Jakarta \\ Jalan Margonda, Depok, 16431, Indonesia \\ E-mail:Bibmuh@gmail.com
}

\author{
Yahdi Kusnadi ${ }^{2}$ \\ ${ }^{2}$ Komputerisasi AkuntansiAMIK BSI Jakarta, \\ Jl. RS. Fatmawati No. 24 Jakarta 12450, Indonesia \\ E-mail :yahdi.ydk@bsi.ac.id
}

\begin{abstract}
Abstrak
Wedding Organizer adalah suatu jasa yang berfungsi secara pribadi membantu calon pengantin dan keluarga dalam perencanaan dan supervisi pelaksanaan rangkaian acara pesta pernikahan sesuai dengan jadwal dan budget yang telah ditetapkan. Perancangan program pernikahan pada Sanggar LarasWedding yang dibuat dengan memanfaatkan teknologi informasi berbasis web dengan tujuan untuk memperluas area promosi dan penjualan paket pernikahan dan mempermudah proses pemesanannya.Sanggar LarasWedding merupakan suatu usaha yang bergerak dibidang pemesanan paket pernikahan yang masih menggunakan sistem manual disetiap kegiatannya. Adanya beberapa kendala seperti pengisian data, proses transaksi penyewaan, pencarian dan pembuatan laporan yang membutuhkan waktu yang cukup lama dan tidak efisien. Bahkan penyimpanan data yang tidak optimal karena masih menggunakan pembukuan transaksi bulanan.Perancangan Program Berbasis Web ini merupakan solusi yang terbaik untuk memecahkan permasalahan - permasalahan yang ada diperusahaan ini, serta dengan perancangan program dapat tercapai suatu kegiatan yang efektif dan efisien, guna menunjang aktifitas pada perusahaan ini.
\end{abstract}

\begin{abstract}
Wedding Organizer is a service that works personally to help bride and groom in planning and supervision of the implementation of wedding party in accordance with schedule and budget that have been determined. The design of wedding program at Studio Laraswedding made by utilizing web-based information technology with the aim to expand the area of promotion and sale of wedding packages and simplify the ordering process. Studio Laraswedding is a business engaged in the booking of wedding packages that still use the manual system in every
\end{abstract}

activity. The existence of some obstacles such as charging data, lease transaction processing, search and preparation of reports that require a long time and inefficient. Even data storage is not optimal because it still uses bookkeeping monthly transactions. Designing Web-Based Program is the best solution to solve the problems - problems that exist in this company, and with the design of the program can be achieved an effective and efficient activities, to support the activities of this company.

Keywords: Program Design, Wedding Package, Web 


\section{Pendahuluan}

Setiap orang punya sebuah impian tentang acara pernikahan yang sempurna. Namun, pesta pernikahan yang sempurna membutuhkan persiapan yang cukup panjang, dan dana yang tidak sedikit. Rutinitas yang sangat tinggi menyebabkan tidak memiliki waktu untuk mempersiapkan segala sesuatunya sendiri. Khususnya bagi mereka yang tinggal di kota metropolitan yang mempunyai tingkat kesibukan yang tinggi. Hanya sedikit waktu yang tersisa untuk keperluan pribadi seperti mempersiapkan pernikahan.

Sehingga diperlukan sistem informasi pemesanan paket pernikahan yang dapat membantu memudahkan user dalam mengelola data yang di perlukan. Serta dengan adanya sistem informasi, maka pekerjaan yang ada dapat diselesaikan secara cepat, tepat dan akurat. Salah satu industri yang berkembang adalah sanggar yang menyediakan jasa untuk acara pernikahan seperti paket-paket pernikahan, pakaian dan rias pengantin, cattering, souvernir, model dekorasi dan lainnya.

\section{Metode Penelitian}

Dalam pembuatan Skripsi ini, penulis menggunakan metode waterfall dalam pengembangan perangkat lunaknya. Dan untuk menunjang dalam penulisan ini, ada beberapa metode pengumpulan data yang dipergunakan untuk mendapatkan keterangan-keterangan guna memenuhi kebutuhan dalam penyusunan Skripsi ini. Metode tersebut adalah sebagai berikut:

\subsection{Teknik Pengumpulan Data}

Untuk mendapatkan data yang diperlukan dalam penelitian, penulis menggunakan beberapa metode sebagai berikut:

\section{A. Metode Pengamatan(Observasi)}

Merupakan cara pengumpulan data secara langsung Pada pihak Sanggar ke lapangan melalui pengamatan terhadap sejumlah objek penelitian dari sejumlah individu yang bersangkutan.

\section{B. Metode Wawancara}

Teknik pengumpulan data dengan mengadakan tanya jawab secara langsung dengan pihak sanggar Laras Wedding terhadap permasalahan yang diteliti.

C. Metode Studi Pustaka (literatur)
Pada metode ini penulis mengumpulkan data dan informasi dengan membaca buku-buku referensi di perpustakaan, catatan-catatan dalam perkuliahan dan juga dari internet yang berhubungan dengan penulisan Tugas Akhir ini guna mendapatkan gambaran mengenai materi yang menjadi sumber referensi.

\subsection{Metode Pengembangan Sistem}

Metode yang digunakan pada pengembangan perangkat lunak ini menggunakan model waterfall (Sukamto dan Shalahudin 2015:28) yang terbagi menjadi 4 tahapan yaitu:

\section{A. Analisa Kebutuhan Software}

Analisa kebutuhan merupakan pengidentifikasian kebutuhan yang diperlukan pada sistem perancangan sistem informasi pemesanan paket pernikahan berbasis web.

B. Desain

Desain perangkat lunak adalah proses multi langkah yang fokus pada desain pembuatan program perangkat lunak harus termasuk struktur data, arsitektur perangkat lunak harus, respresentasi antarmuka, dan prosedur pengkodean.

\section{Code Generation}

Desain harus ditranslasikan ke dalam program perangkat lunak harus. Hasil dari tahap ini adalah perangkat lunak harus sesuai dengan desain yang telah dibuat pada tahap desain.

D. Testing

Pengujian fokus pada perangkat lunak harus secara dari segi lojik (Logic), fungsional dan memastikan bahwa semua bagian sudah diuji. Hal ini dilakukan untuk meminimalisir kesalahan (error) dan memastikan keluaran yang dihasilkan sesuai dengan yang diinginkan.

\section{Hasil dan Pembahasan}

Untuk membantu para konsumen dalam memenuhi kebutuhan akan pelayanan pemesanan paket pernikahan, Sanggar Laras Wedding hadir menyediakan berbagai macam paket pernikahan sesuai dengan keinginan konsumen. Dengan lokasi sanggar yang strategis dan memudahkan para konsumen untuk langsung datang dan dapat bertemu dengan pemilik Sanggar Laras untuk memilih langsung paket pernikahan yang diinginkan 
agar dapat memudahkan para konsumen dalam memenuhi kebutuhannya.

\section{A. Tahapan Analisis}

Pada sistem Sanggar Laras Wedding begitu banyak masyarakat yang ingin mendapatkan informasi lebih tentang pemesanan paket pernikahan sehingga mengharuskan masyarakat untuk datang langsung ke tempat sanggar. Oleh sebab itu muncul ide untuk membuat sebuah halaman web yang akan memudahkan para konsumen untuk memperoleh informasi tentang jasa pernikahan dalam melakukan transaksi secara online. Berikut ini Spesifikasi kebutuhan (System Requitment) pada Sanggar Laras Wedding yaitu:

\section{Halaman Customer :}

A1. Customer dapat melihat melihat isi dari paket-paket pernikahan yang ditawarkan

A2. Customer dapat melakukan konsultasi sebelum memilih paket pernikahan.

A3. Customer dapat melakukan order atau pemesanan.

A4. Customer melakukan pembayaran dan menerima bukti pembayaran.

\section{Halaman Pengunjung:}

B1. Pengunjung dapat melihat website Sanggar Laras Wedding.

B2. Pengunjung dapat melakukan pendaftaran sebagai member.

B3. Pengunjung dapat melihat pilihat paket dan gallery poto paket pernikahan

\section{Halaman Admin :}

B1. Pengunjung dapat melihat website Sanggar Laras Wedding.

B2. Pengunjung dapat melakukan pendaftaran sebagai member.

B3. Pengunjung dapat melihat pilihat paket dan gallery poto paket pernikahan
B. Use Case Diagram

1. Use Case Diagram Halaman Customer

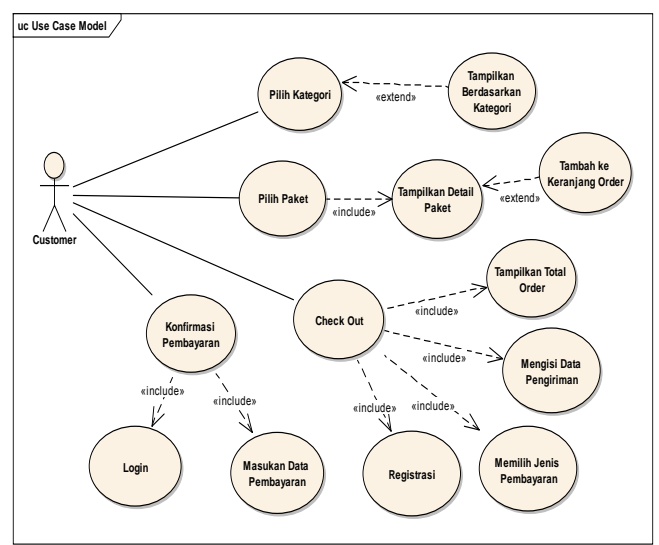

Gambar III. 1

Use Case Diagram Halaman Customer

2. Use Case Diagram Halaman Admin

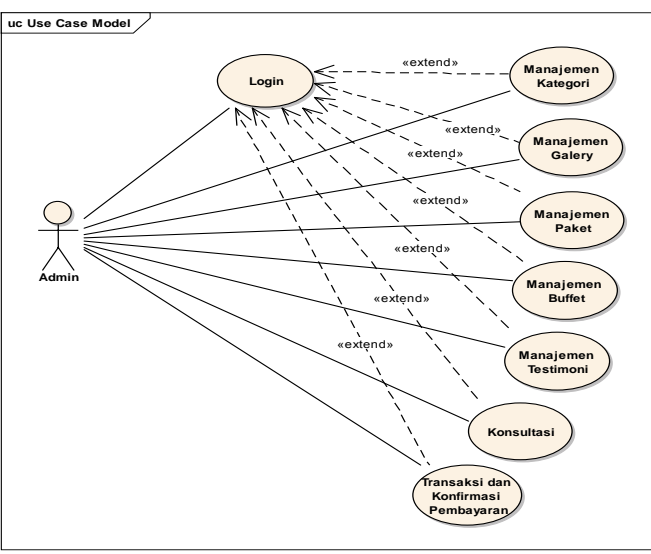

Gambar III.2

Use Case Diagram Halaman Admin

C. Activity Diagram

1. Activity Diagram Login Customer

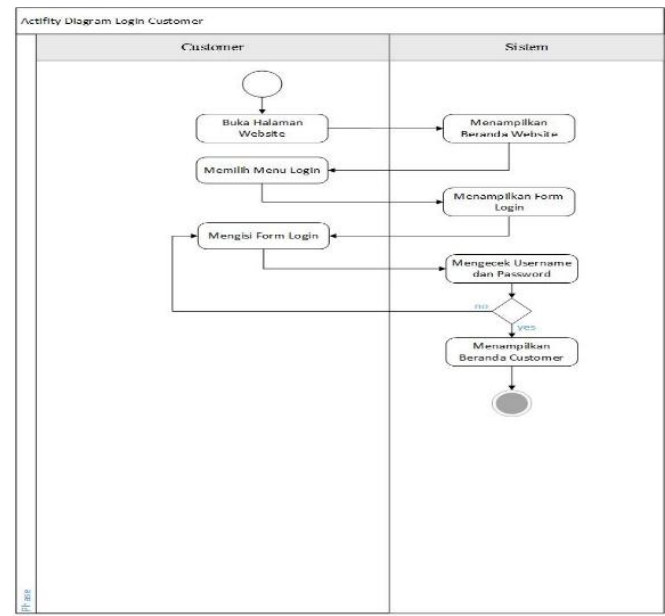


Gambar III.3

Activity Diagram Login Customer

2. Activity Diagram Pilih Paket Pernikahan

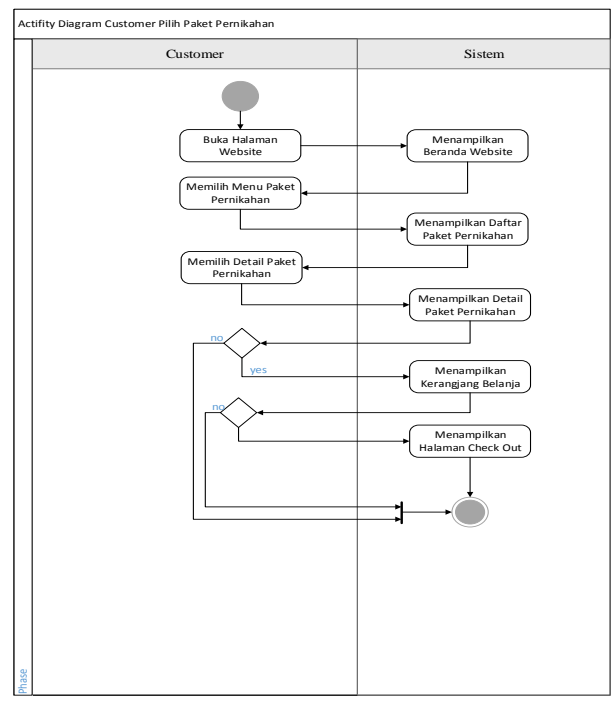

Gambar III.4

Activity Diagram Pilih Paket Pernikahan

D. Component Diagram

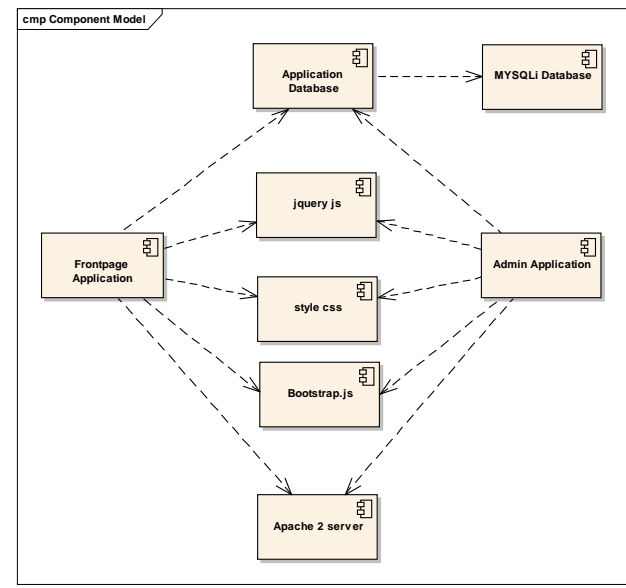

Gambar III.5

Component Diagram

E. Deployment Diagram

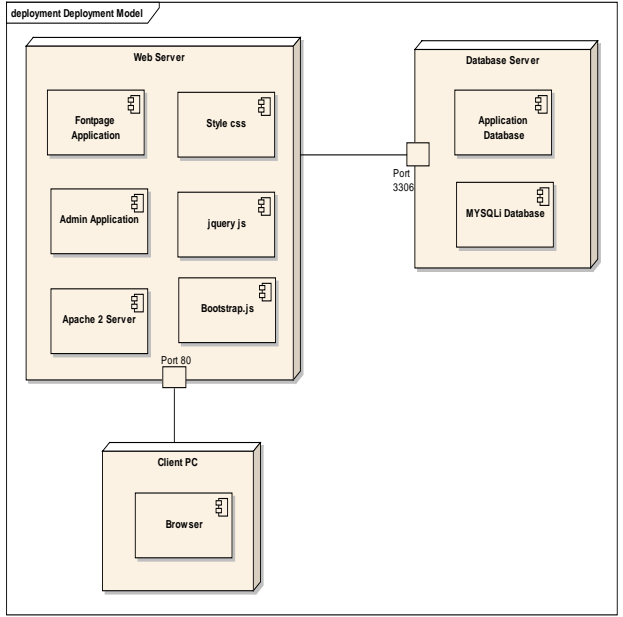

Gambar III.6

Deployment Diagram

F. User Interface

1. Tampilan Halaman Customer

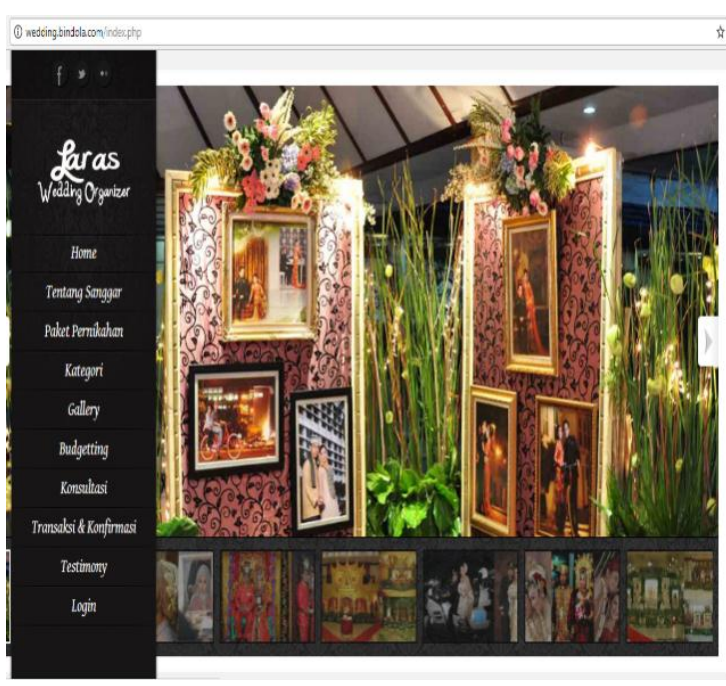

Gambar III.7

Tampilan Halaman Customer

2. Tampilan Login Customer

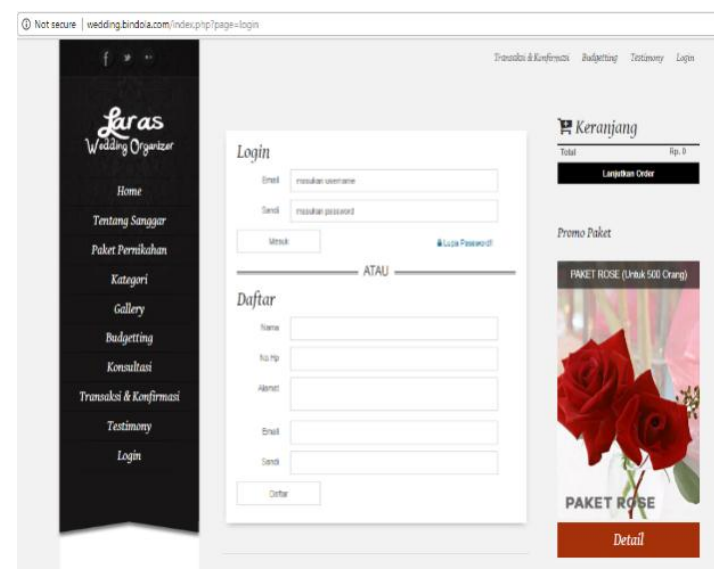

Gambar III. 8 
Tampilan Login Customer

3. Tampilan Halaman Admin

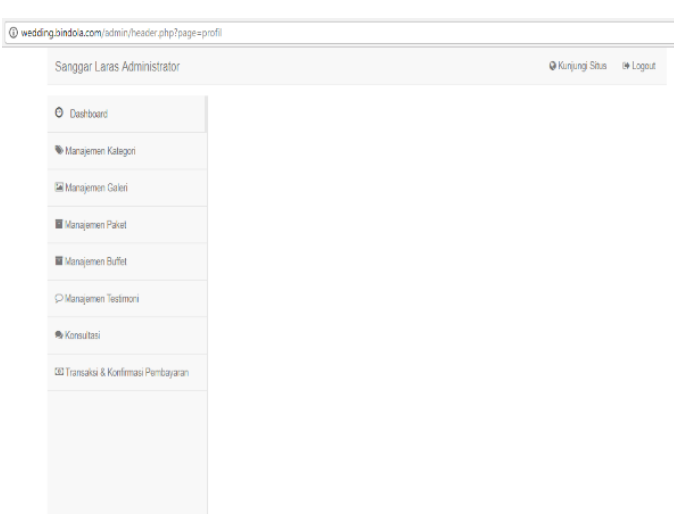

Gambar III.9

Tampilan Halaman Admin

4. Tampilan Transaksi Pembayaran

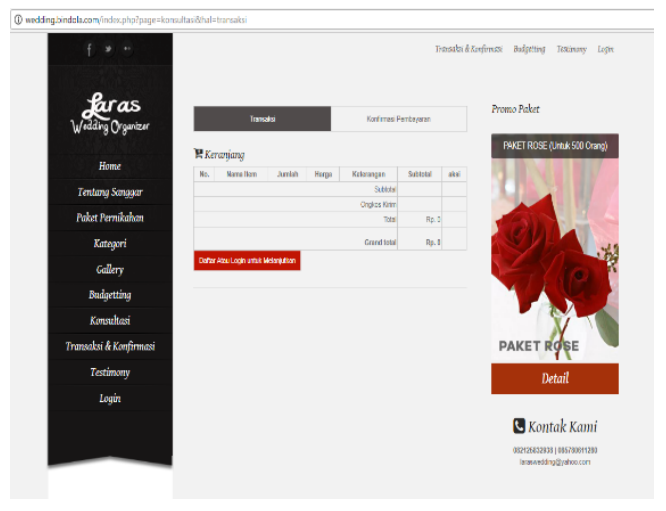

Gambar III.10

Tampilan Transaksi Pembayaran

5. Tampilan Konfirmasi Pembayaran

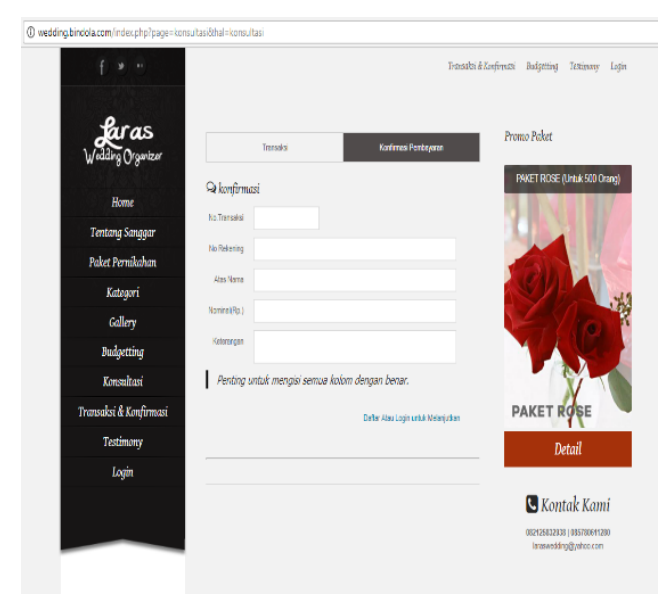

Gambar III.11

Tampilan Konfirmasi Pembayaran

\section{Kesimpulan}

Hermawan, Indra dan Dian Ade Kurnia. (2014). Sistem Informasi Pemesanan Paket Pengantin Berbasis Web Pada Yuni Salon Duku Puntang.
Dari penjelasan pada bab - bab sebelumnya, penulis dapat merangkum beberapa kesimpulan, yaitu sebagai berikut :

1. Program pemesanan paket pernikahan dapat segera diterapkan pada Sanggar Laras Wedding untuk membantu calon pengantin dalam mempersiapkan acara pernikahan.

2. Program pemesanan paket pernikahan ini dilengkapi dengan adanya from transaksi dan konsultasi akan mempermudah customer dalam melakukan proses transaksi pemesanan, sehingga tidak akan menyita waktu yang cukup lama.

3. Dengan adanya paket - paket pernikahan yang tersedia pada Sanggar Laras wedding, sanggat membantu customer dalam menentukan pilihan paket yang akan digunakan pada acara pernikahan.

\section{Saran}

Dengan selesainya program Perancangan Sistem Informasi Pemesanan Paket Pernikahan Berbasis web pada Sanggar Laras Wedding Bogor ini, penulis memiliki beberapa saran sekiranya dapat ditanggapi oleh semua pihak, sebagai berikut :

1. Isi situs web seharusnya di maintance oleh admin secara berkala sesuai dengan perkembangan yang terjadi, guna memberikan informasi yang akurat.

2. Pengembangan program pemesanan paket pernikahan perlu ditingkatkan agar kinerja dapat berjalan maksimal dan perlu dilakukan perawatan program untuk mencegah terjadinya error.

3. Dengan adanya program pemesanan paket pernikahan pada Sanggar Laras Wedding secara online dapat mendukung pengembangan program pernikahan, dan memudahkan calon pengantin mendapatkan informasi mengenai pemesanan paket pernikahan, agar selanjutnya dikembangkan dengan model komunikasi yang lebih cepat seperti fitur chatting atau sebagainya, agar dapat tercipta komunikasi antara pihak sanggar dan customer dengan bantuan pemesanan paket pernikahan secara menyeluruh.

\section{Daftar Pustaka}

Vol.12 No.2 Sekolah Tinggi Manajemen Informatika STMIK - IKMI - Desember 2014 http://docplayer.info/32561311-Sistem- 
informasi-pemesanan-paket-pengantinberbasis-web-pada-yuni-salon-duku-puntangkabupaten-cirebon.html

Hidayatullah, Priyanto dan Jauhari Khairul Kawistara. (2014). Pemrograman WEB, Bandung: Informatika.

Ladjamudin, Bin Al-Bahra. (2013). Rekayasa Perangkat Lunak. Palembang : Maxikom

Madcoms.(2011). Dreamweaver CS5 dan PHP MySQL untuk pemula. Yogyakarta: Andi Offset.

Sibero, AlexanderF.K (2011). Kitab Suci Web Programming. Yogyakarta: MediaKom.
Sukamto, Rosa Ariyani dan M. Salahuddin. (2015). Rekayasa perangkat Lunak. Bandung: Modula

Vermaat, Shelly Cashman. (2007). Discovering Computers "Menjelajah Dunia Komputer" FUNDAMENTAL. Third Edition. Salemba: Infotek.

http://elib.unikom.ac.id/files/disk1/575/jbptunik ompp-gdl-widyahardh-28737-9-unikom wi.pdf (20 Juli 2017)

Wong, Jony. (2010). Internet Marketing For Beginners. Jakarta : PT Elex Media Komputindo

http://elib.unikom.ac.id/files/disk1/575/jbptunik ompp-gdl-widyahardh-28737-9-unikom_wi.pdf (20 Juli 2017 